\title{
Abscisic Acid: A Novel Nutraceutical for Glycemic Control
}

\author{
Elena Zocchi ${ }^{*}$, Raquel Hontecillas ${ }^{2,3 *}$, Andrew Leber ${ }^{2}$, Alexandra Einerhand ${ }^{2}$, \\ Adria Carbo' ${ }^{2}$, Santina Bruzzone ${ }^{1}$, Nuria Tubau-Juni ${ }^{3}$, Noah Philipson ${ }^{2}$, \\ Victoria Zoccoli-Rodriguez ${ }^{2}$, Laura Sturla ${ }^{1}$ and Josep Bassaganya-Riera ${ }^{2,3}$
}

${ }^{1}$ Department of Experimental Medicine, Section of Biochemistry and Center of Excellence for Biomedical Research, University of Genoa, Genoa, Italy, ${ }^{2}$ BioTherapeutics Inc., Blacksburg, VA, United States, ${ }^{3}$ Nutritional Immunology and Molecular Medicine Laboratory, Biocomplexity Institute of Virginia Tech, Blacksburg, VA, United States

\section{OPEN ACCESS}

Edited by:

Lorraine M. Sordillo,

Michigan State University,

United States

Reviewed by:

Matteo A. Russo,

Sapienza Università

di Roma, Italy

S. Raza Shaikh,

East Carolina University,

United States

*Correspondence:

Elena Zocchi

ezocchi@unige.it;

Raquel Hontecillas

rmagarzo@me.com

Specialty section:

This article was submitted to

Nutritional Immunology,

a section of the journal

Frontiers in Nutrition

Received: 13 April 2017

Accepted: 19 May 2017

Published: 13 June 2017

Citation:

Zocchi E, Hontecillas R, Leber A, Einerhand A, Carbo A, Bruzzone S,

Tubau-Juni N, Philipson N,

Zoccoli-Rodriguez V. Sturla L and

Bassaganya-Riera J (2017) Abscisic

Acid: A Novel Nutraceutical for

Glycemic Control.

Front. Nutr. 4:24.

doi: 10.3389/fnut.2017.00024
Abscisic acid is naturally present in fruits and vegetables, and it plays an important role in managing glucose homeostasis in humans. According to the latest U.S. dietary survey, about $92 \%$ of the population might have a deficient intake of ABA due to their deficient intake of fruits and vegetables. This review summarizes the in vitro, preclinical, mechanistic, and human translational findings obtained over the past 15 years in the study of the role of ABA in glycemic control. In 2007, dietary ABA was first reported to ameliorate glucose tolerance and obesity-related inflammation in mice. The most recent findings regarding the topic of ABA and its proposed receptor lanthionine synthetase C-like 2 in glycemic control and their interplay with insulin and glucagon-like peptide- 1 suggest a major role for ABA in the physiological response to a glucose load in humans. Moreover, emerging evidence suggests that the ABA response might be dysfunctional in diabetic subjects. Follow on intervention studies in healthy individuals show that low-dose dietary ABA administration exerts a beneficial effect on the glycemia and insulinemia profiles after oral glucose load. These recent findings showing benefits in humans, together with extensive efficacy data in mouse models of diabetes and inflammatory disease, suggest the need for reference ABA values and its possible exploitation of the glycemia-lowering effects of ABA for preventative purposes. Larger clinical studies on healthy, prediabetic, and diabetic subjects are needed to determine whether addressing the widespread dietary ABA deficiency improves glucose control in humans.

Keywords: lanthionine synthetase C-like 2, abscisic acid, diabetes, prediabetes, metabolic syndrome

\section{INTRODUCTION}

\section{ABA Is a Conserved Signaling Molecule among Species}

$\mathrm{ABA}$ is a naturally occurring isoprenoid compound that was originally identified in plants in the 1960 s (1). ABA is also present in metazoans, from sponges up to mammals including humans, and so it is well conserved. The chemistry and physiology of $\mathrm{ABA}$ and its analogs is described by Milborrow (2). The naturally occurring enantiomeric form of ABA is (S)-ABA.

Abbreviations: ABA, abscisic acid; cADPR, cyclic ADP-ribose; cAMP, cyclic adenosine monophosphate; GLP-1, glucagonlike peptide-1; GLUT4, glucose transporter 4; LANCL2, lanthionine synthetase C-like 2; PKA, protein kinase A; TZD, thiazolidinedione. 
Plants have evolved various signaling mechanisms enabling them to withstand the multiple environmental conditions to which they are exposed, including variable water and nutrient availability, temperature variations, and excess ultraviolet-B light. Most of the plant responses to these abiotic conditions are mediated by abscisic acid. The ABA-signaling pathway is initiated by its binding to the specific receptor complex RCARs/PYR1/PYLs, leading to inactivation of type $2 \mathrm{C}$ protein phosphatases and activation of kinases, which mediate ABA-dependent changes in metabolism, gene expression, and ion channel activity $(3,4)$.

Interestingly, ABA plays essentially the same role in lower Metazoa (sponges and hydroids), where it mediates the responses of these sessile marine organisms to variations in water temperature and light. In sponges, the oldest Metazoa, their evolution dating back to 600 million years, temperature-signaling occurs via ABA (5). In Axinella polypoides, an increase of the water temperature results in an increased ABA synthesis and in the ABAmediated stimulation of water filtration and oxygen consumption (6). Hydroids follow sponges in the evolutionary tree, having sensory, nerve, muscle and epithelial cells, a digestive cavity, and a rudimentary nervous system, but share with sponges a sessile lifestyle. In Eudendrium racemosum, light stimulates endogenous ABA synthesis and ABA stimulates stem cell-mediated tissue regeneration (7).

\section{ABA Origin and Role in Mammals}

In the human body, ABA naturally originates from dietary sources and endogenous production through the carotenoid biogenesis pathway. ABA was first described in the brain of pigs and rats (8). The fact that animals fed a synthetic, ABAfree diet had ABA levels even higher than those of controls fed a vegetable diet was taken as an indirect proof that ABA was endogenously produced. To this point, a more recent observation allows the conclusion that ABA is indeed an endogenously produced signaling molecule: plasma ABA (ABAp) levels increase significantly in healthy humans after an (ABA-free) glucose load (9). On the one hand, this observation points to $\mathrm{ABA}$ as being endogenously synthesized; plus it suggests a role for $\mathrm{ABA}$ in the physiological response to glucose intake, a role until then shared by insulin and by the incretin glucagon-like peptide-1 (GLP-1).

Several in vitro observations support the conclusion that ABA is indeed endogenously produced by human and murine cells: granulocytes (10), monocytes and macrophages $(11,12)$, insulin-releasing cells (13), mesenchymal stem cells (MSCs) (14), hemopoietic progenitors (HP) (15), adipocytes (9), keratinocytes (16), and fibroblasts (17), all have been shown to produce and release ABA when exposed to cell-specific stimuli. The cellspecific functional effects activated by $\mathrm{ABA}$ in these cell types are in line with a conserved role of $\mathrm{ABA}$ as a signal relating cell response to changing environmental conditions. The fact that several different cell types can produce ABA implies that ABAp may derive from multiple sources. Markedly reduced ABAp levels were measured in patients with type 1 diabetes as compared with healthy individuals of similar age and body mass index (9), suggesting that $\beta$-pancreatic cells may be a relevant source of ABA. High glucose concentrations can stimulate ABA release from human adipose tissue biopsies in vitro (9) and the fact that adipose tissue accounts for a substantial amount of body weight, even in non-obese subjects, may make it another significant source of ABAp, in addition to pancreatic $\beta$-cells.

\section{Conservation of ABA-Signaling Pathway Hallmarks from Plants to Lower Metazoa and Mammals: G-Protein-Coupled Receptor, Protein Kinase A (PKA), CADPR, and $\mathrm{Ca}^{2+}$}

One of the chief functions of $A B A$ in plants is to reduce guard cell turgor, thereby contributing to the conservation of water during periods of drought. This functional response triggered by $A B A$ is mediated by an increase of the cytoplasmic $\mathrm{Ca}^{2+}$ concentration $\left(\mathrm{Ca}_{\text {cyt }}^{2+}\right)$ in guard cells, induced by the intracellular $\mathrm{Ca}^{2+}$-mobilizing second messenger cyclic ADP-ribose (cADPR) $(18,19)$. cADPR is produced from $\mathrm{NAD}^{+}$by ADP-ribosyl cyclases (ADPRCs), enzymes with an ancient evolutionary origin, being ubiquitously expressed from plants to lower and higher Metazoa (20).

Intriguingly, the signaling pathway downstream of $\mathrm{ABA}$ stimulating water filtration in sponges and tissue regeneration in hydroids shares with the plant ABA-mediated stomatal closure the same ADPRC-generated second messenger, $\operatorname{cADPR}(6,7)$. ABA has been reported to activate the cyclase activity of Arabidopsis ADPRC, in the absence of protein synthesis, although the mechanism of activation was not elucidated (21). In Eudendrium and in Axinella, activation by ABA of the ADPRC occurs via a PKA-dependent phosphorylation. Indeed, the signaling pathway downstream of ABA in Axinella and in Eudendrium is similar and involves the sequential activation of PKA, phosphorylation and activation of ADPRC, cADPR overproduction, and increase of $\mathrm{Ca}_{\text {cyt }}^{2+}(5,7)$.

The signaling pathway downstream of $\mathrm{ABA}$ in human granulocytes is strikingly similar to the one unveiled in lower Metazoa, and it involves an ADPRC (CD38) and its product cADPR (Figure 1). In addition to activating adenylate cyclase (AC), ABA also activates phospholipase C (PLC), with the consequent overproduction of inositol triphosphate $\left(\mathrm{IP}_{3}\right)$; thus, the increase of $\mathrm{Ca}_{\text {cyt }}^{2+}$ triggered by $\mathrm{ABA}$ in granulocytes is mediated by both cADPR and $\mathrm{IP}_{3}$ (Figure 1). The G-protein coupled to the ABA receptor was identified as Gi by its sensitivity to pertussis toxin (PTX) (10). The mechanism through which Gi mediates the activation of both PLC and AC was elucidated by means of transfection experiments, performed on human granulocytes with a chimeric G-protein, resulting from the fusion of Gai with the last five aminoacids of $\mathrm{G} \alpha \mathrm{q}(\mathrm{G} \alpha \mathrm{q} / \mathrm{i})$, and with transducin $(\alpha \mathrm{t})$, a scavenger of $\beta \gamma$ subunits. Overexpression of $\mathrm{G} \alpha \mathrm{q} / \mathrm{i}$ increases the contribution of $\mathrm{IP}_{3}$ to the $\mathrm{Ca}_{\text {cyt }}^{2+}$ rise induced by $\mathrm{ABA}$ and results in a fast and transient $\mathrm{Ca}_{\text {cyt }}^{2+}$ increase, that becomes evident when the contribution of cADPR to the $\mathrm{Ca}_{\text {cyt }}^{2+}$ rise is prevented by the cADPR antagonist 8Br-cADPR (22). Overexpression of $\alpha$ t dampens the ABA-induced $\mathrm{Ca}_{\text {cyt }}^{2+}$ increase, demonstrating that the $\beta \gamma$ subunits of Gi are responsible for the activation of both PLC and $\mathrm{AC}$ (22). A role for both cADPR and $\mathrm{IP}_{3}$ in the ABA-triggered increase of $\mathrm{Ca}_{\text {cyt }}^{2+}$ has been reported in granulocytes (10) and in monocytes (12). 


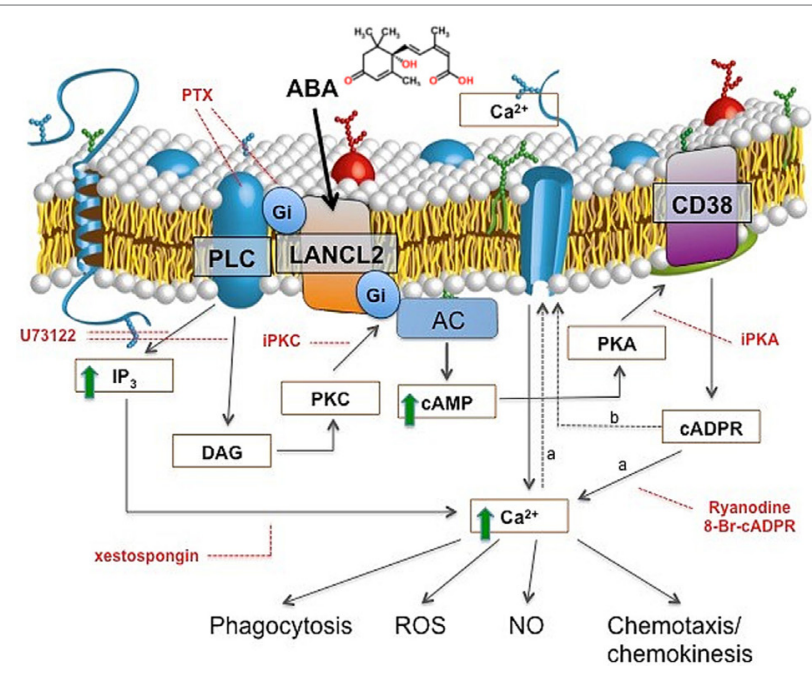

FIGURE 1 | ABA signaling in human granulocytes. The interaction of ABA with a G-protein-coupled plasmamembrane receptor triggers: (i) activation of phospholipase $\mathrm{C}$ (PLC), overproduction of inositol triphosphate $\left(\mathrm{IP}_{3}\right)$, and stimulation of a PKC-dependent adenylate cyclase (AC); (ii) activation of $A C$, overproduction of cAMP, protein kinase $A(P K A)$-mediated stimulation of ADP-ribosyl cyclase, and increase of [CADPR];. Downstream of cyclic ADP-ribose (CADPR), two mechanisms (dotted lines) might cooperate to induce the observed increase of the $\left[\mathrm{Ca}^{2+}\right]$ : extracellular $\mathrm{Ca}^{2+}$ influx through store-operated $\mathrm{Ca}^{2+}$ entry (a), or, direct gating of a plasmamembrane $\mathrm{Ca}^{2+}$ channel by cADPR (b). Site-specific inhibitors of the ABA-signaling pathway are indicated in red. PTX, pertussis toxin; U73122, PLC inhibitor; xestospongin, $\mathrm{IP}_{3}$-specific $\mathrm{Ca}^{2+}$-channel blocker; I-PKA and I-PKC, PKA- and PKC-specific myristoylated (peptide inhibitors); 8-Br-cADPR, specific cADPR antagonist; Ry, Ryanodine (cADPR-specific $\mathrm{Ca}^{2+}$-channel blocker). The increased $\left[\mathrm{Ca}^{2+}\right]_{i}$ levels stimulate functional responses: phagocytosis, release of ROS and NO, chemokinesis, and chemotaxis to ABA.

Conservation of the ABA-signaling pathway sequentially involving AC, cAMP, PKA-dependent ADPRC activation, cADPR overproduction, and $\mathrm{Ca}_{\text {cyt }}^{2+}$ increase from sponges to lower and higher Metazoa points to its presence at a very early stage of evolution, in a precursor common to plants and animals. This may suggest an evolutionarily conserved role of ABA in adaptation to environmental stresses that has yet to be fully elucidated in humans.

\section{The Mammalian ABA Receptor: Lanthionine Synthetase C-Like 2 (LANCL2)}

The Arabidopsis membrane-bound ABA receptor GCR2 shares a high amino acid identity with the mammalian peptide-modifying lanthionine synthetase C-like (LANCL) protein family (23), and the LANCL protein family in turn shows structural similarities with the prokaryotic lanthionine synthetase component $\mathrm{C}$ proteins (24) involved in the synthesis of lanthionine-containing antimicrobial peptides known as lantibiotics (25) such as nisin, which are used to prevent bacterial growth in foods. However, lantibiotics are not produced in animals; thus, mammalian LANCL proteins must have a different function than prokaryotic LanC proteins. The human genome contains three LANCL genes, LANCL1, LANCL2, and LANCL3, on chromosomes 2, 7, and the $\mathrm{X}$ chromosome, respectively $(26,27)$. In human epithelial cells overexpressing LANCL1 or LANCL2 fused to the green fluorescent protein (LANCL1-GFP and LANCL2-GFP), LANCL1-GFP is mainly found in the cytosol and in the nucleus, whereas LANCL2-GFP is associated with the plasmamembrane through N-terminal myristoylation (28). Recently, it has been demonstrated that the demyristoylation of LANCL2 by chemical or genetic means triggers its nuclear translocation. The nuclear enrichment of native LANCL2 was also induced by ABA treatment, suggesting that human LANCL2 is a non-transmembrane G-protein-coupled receptor susceptible to hormone-induced nuclear translocation (29).

Several lines of evidence support the conclusion that LANCL2 is a mammalian receptor for ABA. Sturla et al. (22) showed that LANCL2 was necessary for ABA binding and signaling in four different cell types (granulocytes, HeLa cells, and RIN-m and INS-1 cells) from two mammalian species: (i) silencing of LANCL2 abrogated the ABA-induced increase of the $\mathrm{Ca}_{\text {cyt }}^{2+}$ and of cAMP in human granulocytes and also prevented the ABA-triggered functional response in these cells; (ii) LANCL2 overexpression conversely potentiated the $\mathrm{Ca}_{\text {cyt }}^{2+}$ increase induced by $\mathrm{ABA}$ in granulocytes and conferred $A B A$ responsiveness in terms of $\mathrm{Ca}_{\text {cyt }}^{2+}$ and of cAMP increase to CD38 ${ }^{+} \mathrm{HeLa}$; and finally, LANCL2 silencing abrogated the ABA-induced biochemical (increase of the $\left[\mathrm{Ca}^{2+}\right]_{i}$ and of the $[\mathrm{cAMP}]_{i}$ ) and functional (insulin release) responses in two different rat insulinoma cell lines. In silico and in vitro studies on the recombinant protein confirmed direct ABA binding to human LANCL2 (see ABA Improves Glucose Tolerance in $\mathrm{db} / \mathrm{db}$ Mice Fed a High-Fat Diet).

\section{ABA Regulates Glucose Homeostasis in Mammals}

Two groups independently hypothesized and experimentally validated the role of $\mathrm{ABA}$ in regulating glucose metabolism. Zocchi and colleagues followed an evolutionary reasoning: in plants, ABA lies at the crossroad between physical, nutrient, and parasitic stress responses. Its conservation in lower Metazoa suggested that it might have similar functions in higher Metazoa: indeed, ABA production occurs in human granulocytes (our first line of defense against pathogens) stimulated with physical or chemical stimuli and that ABA activates their defensive functions (10). That acute physical stress induces hyperglycemia and that the second messengers involved in ABA signaling in granulocytes, CAMP and CADPR, played a role in the signaling leading to glucose-induced insulin secretion $(30,31)$ suggested to explore the possible role of $\mathrm{ABA}$ in the arguably most important aspect of mammalian nutrient disposal, i.e., insulin release (13).

Bassaganya-Riera and colleagues were drawn to the study of the effect of ABA on mammalian glucose homeostasis based upon the structural similarities between ABA and the thiazolidinedione (TZD) class of insulin-sensitizing antidiabetic drugs, which bind to the ligand-binding domain of the transcription factor PPAR $\gamma$ and activate the transcription of several genes involved in glucose and lipid metabolism. They provided the first evidence in vivo that $\mathrm{ABA}$ exerts glucose-normalizing effects when administered to genetically obese $\mathrm{db} / \mathrm{db}$ mice fed a high-fat diet (32) and to mice 
with diet-induced obesity (33). Moreover, ABA was shown to have similar efficacy to that of TZDs in mouse models of diabetes (32). However, ABA was shown to bind LANCL2 and to act independently of PPAR $\gamma$ (34). The next section will describe in more detail the in vitro and in vivo evidence accumulated until now, which confirms and expands our view of ABA as an endogenous regulator of glucose disposal in mammals and it highlights the fact that ABA is naturally present in our diet thereby providing a natural way to balance glucose levels in healthy individuals and manage glycemic control in prediabetic, diabetic, and metabolic syndrome patients.

\section{ABA: A DIETARY COMPOUND PRESENT IN FRUITS AND VEGETABLES}

Many countries, including the United States, have a deficient intake of fruits and vegetables. On a country-wide scale, this results in a broad 1.5- to 2-fold reduction in consumption of phytochemicals (35). When individuals who meet fruit and vegetable recommendations are compared with those who do not, notable reductions in carotenoids (twofold), flavonones (threefold), and ellagic acid (fivefold) occur (36). These magnitudes of deficiencies have been linked to increased risk for the development of cardiovascular disease, metabolic disease, and cancer $(37,38)$.

Specifically, ABA is present in a variety of fruits and vegetables as shown in Table $\mathbf{1}$. The concentration varies depending on the type of fruit or vegetable but on average the concentration of $\mathrm{ABA}$ is $0.29 / \mathrm{mg} / \mathrm{kg}$ wet weight of vegetable and $0.62 \mathrm{mg} / \mathrm{kg}$ of wet weight of fruit. According to the latest published dietary survey data from 2009 to 2012 (39), US adults aged 20 years or older consumed on average 1.05 servings/day of whole fruits

TABLE 1 | Concentration of ABA in various foodstuffs.

Concentration of $A B A$ in various fruits and vegetables

\begin{tabular}{llc}
\hline Food category & ABA level $\mathbf{( m g} / \mathbf{k g})$ & Reference \\
\hline Fruits ${ }^{\star}$-average total & 0.62 & \\
Apple & 0.30 & $(40)$ \\
Apricot & 0.32 & $(40)$ \\
Avocado & 2.0 & $(41)$ \\
Banana & 0.22 & $(40)$ \\
Bilberry & 0.4 & $(40)$ \\
Citrus & 1.25 & $(42)$ \\
Fig & 0.72 & $(40)$ \\
Pepper fruit & 0.25 & $(43)$ \\
Persimmon & 0.10 & $(44)$ \\
Vegetables ${ }^{*}$-average total & 0.29 & \\
Barley & 0.20 & $(45)$ \\
Cucumber & 0.09 & $(46)$ \\
Maize & 0.33 & $(47)$ \\
Pea & 0.13 & $(48)$ \\
Potato & 0.09 & $(49)$ \\
Soybean & 0.79 & $(50)$ \\
Tomato & 0.20 & $(46)$ \\
Wheat & 0.15 & $(51)$ \\
\hline
\end{tabular}

${ }^{*}$ Fruits and vegetables are categorized according to Rehm et al. Vegetables including legumes, tomato, and potato. and fruit juices (= $189 \mathrm{~g} /$ day) and 1.74 servings of vegetables per day including legumes and potatoes (229 g/day). Based on averages, a U.S. citizen of 20 years and older would consume $189 \times 0.62=117.2 \mu \mathrm{g}$ of ABA per day derived from fruits and $229 \times 0.29=66.4 \mu \mathrm{g}$ of ABA per day derived from vegetables. Thus, a US adult would consume an average of $184 \mu \mathrm{g}$ of ABA per day derived from the 2.79 servings/day of fruits and vegetables.

The current recommendation is to eat $\geq 4.5$ servings/day, which would lead to $\geq 297 \mu$ g of ABA per day in an ideal situation, but only $8 \%$ of the US adult population is meeting the dietary recommendations for fruits and vegetables of American Heart Association 2020 Strategic Goals (39). This means that $92 \%$ of the population is receiving an ABA-deficient diet according to these recommendations. It remains unclear what the ABA deficiency means in terms of long-term health effects, but it is tempting to speculate that the ABA deficiency might be a risk factor involved in the onset of diabetes and cardiovascular disease.

In a study designed to assess the effects of phytochemicals on health, an increase of combined fruit and vegetable intake by $480 \mathrm{~g} /$ day tripled the amount systemically available ABA after 6 weeks, identified ABA as one of three novel biomarkers (along with cyclohexadienecarboxylic acid and cyclohexanecarboxylic acid) and strongly correlated with decreased CVD risk biomarkers in a human trial (52). While a dietary adjustment of this magnitude may be unrealistic in the general population, a standard diet, with insufficient fruit and vegetable intake, clearly presents suboptimal ABA concentrations throughout the body. Currently, insufficient data on the necessity of phytochemical intake and the complexity of interactions among the 8,000 identified dietary bioactive compounds limit the ability to assign a recommended daily intake of ABA and similar compounds (53). However, by elucidating specific effects of its deficiency and benefits of its supplementation, ABA can become an accepted nutritional quantity like similar compounds, lutein and zeaxanthin with retinal health, for certain medical disorders associated with altered glucose metabolism and homeostasis.

\section{IN VITRO EFFECTS OF ABA ON GLUCOSE AND LIPID METABOLISM}

\section{ABA Stimulates Insulin Release from Pancreatic $\beta$-Cells and GLP-1 Release from Enteroendocrine Cells}

High glucose concentrations stimulate production and release of ABA from rodent insulinoma cells and from human pancreatic $\beta$-cells (13). Nanomolar ABA in turn stimulates glucoseindependent (i.e., in the absence of glucose) and potentiates glucose-dependent (i.e., in the presence of either low or high glucose) insulin release (13). The signaling pathway of ABA in $\beta$-cells involves its receptor LANCL2 (22), and the sequential activation of PTX-sensitive Gi, AC, cAMP production, PKA-mediated phosphorylation and activation of the ADPRC CD38, followed by accumulation of cADPR (13).

Oral glucose load stimulates insulin release from pancreatic $\beta$-cells principally via the incretin GLP-1, which is believed to 
account for up to $70 \%$ of glucose-stimulated insulin release (54). GLP-1 is produced and released into the blood by enteroendocrine cells (L cells) in response to high glucose concentrations in the gut. ABA induces glucose-independent GLP-1 release in the human L cell line hNCI-H716 through a cAMP/PKA-dependent mechanism and also enhances GLP-1 transcription (55). An increase of plasma GLP-1 (GLP-1p) is observed also in vivo, upon oral ABA administration in fasted rats (55). Interestingly, GLP-1 stimulates ABA release from an insulinoma cell line and from human islets, approximately 10 - and 2 -fold in low and high glucose, respectively (9). Altogether, these results suggest the existence of a positive feedback mechanism between ABA and GLP-1 activated by hyperglycemia, whereby ABA stimulates GLP-1 production by L cells and GLP-1 stimulates ABA release from $\beta$-cells.

The increases of the GLP-1 and ABA plasma concentrations that normally follow oral glucose intake are impaired in type 2 diabetes (T2D) $(56,57)$, further supporting the hypothesis of a mutual regulation between these molecules. Besides stimulating insulin release, GLP-1 has several beneficial effects on the cardiovascular system, including stimulation of cardiomyocyte glucose uptake in vitro and prevention of ischemic-reperfusion injury and improvement of myocardial performance in vivo [reviewed by Sarraju et al. (58)]. Thus, understanding the molecular cross talk between ABA and GLP-1 may shed new light on the physiology as well as the dysfunction of GLP-1-mediated cardiometabolic protection. In this respect, $\mathrm{ABA}$ administration improved atherosclerosis-induced hypertension, inflammatory immune cell recruitment into the aortic root wall, increased plasma triglyceride (TG) and non-esterified fatty acid concentrations, and upregulated aortic eNOS expression in $\mathrm{ApoE}^{-/-}$mice (59), suggesting that $\mathrm{ABA}$ elicits a local antiatherogenic effect in the arterial wall of mice and supports its cardiometabolic protective role.

\section{ABA Stimulates Glucose Uptake in Rodent Adipocytes and Myoblasts}

$\mathrm{ABA}$ at nanomolar concentrations stimulates glucose uptake by differentiated murine adipocytes and by rat myoblasts in vitro, to a similar extent as insulin at the same concentration (9). ABA increases glucose transporter 4 (GLUT4) translocation to the plasmamembrane in both cell types (9) and stimulates the Ser phosphorylation of Akt similarly to insulin (9).

Insulin-independent stimulation of GLUT4 translocation by $\mathrm{ABA}$ in adipocytes is particularly relevant to the glycemia-lowering effect of ABA. Mice with the adipose tissue-specific ablation of GLUT4, but normal GLUT4 expression in muscle, are insulin resistant and have an increased risk of developing overt diabetes (60); adipose tissue-specific GLUT4 KO mice are insulin resistant also in liver and muscle (61). Overexpression of GLUT4 in the adipose tissue can prevent diabetes in mice defective for muscle GLUT4 expression (61). Of note, LANCL2 facilitates phosphorylation of Akt by mTORC2 via direct physical interactions with both the kinase and the substrate (62). The active mTORC2 causes translocation of GLUT4 to the plasma membrane and glucose uptake in liver cells (63). Bassaganya-Riera et al. published for the first time that ABA treatment prevents LPS-induced downregulation of Glut4 in spleens of mice (34).

\section{ABA AMELIORATES GLUCOSE TOLERANCE AND ADIPOSE TISSUE INFLAMMATION}

\section{ABA Improves Glucose Tolerance in $\mathrm{db} / \mathrm{db}$ Mice Fed a High-Fat Diet}

Bassaganya-Riera and colleagues demonstrated for the first time that $\mathrm{ABA}$ improves glucose tolerance in genetically obese $\mathrm{db} / \mathrm{db}$ mice fed a high-fat diet and to mice with diet-induced obesity $(32,33)$. In another study, we demonstrated that ABA performs within 98\% similarity to the market drug, Avandia, a PPAR $\gamma$ agonist. However, as opposed to TZDs, ABA does not bind to PPAR $\gamma$ (34). Of note, treatment with ABA helped reduce inflammatory markers in the adipose tissue. Specifically, treatment with ABA downregulated monocyte chemoattractant protein-1 (MCP-1) expression and the infiltration of pro-inflammatory $\mathrm{F} 4 / 80^{+} \mathrm{CD} 11 \mathrm{~b}^{+}$macrophages in the stromal vascular fraction of adipose tissue (34). Insulin has been shown to be less effective in improving glucose tolerance in an inflamed environment due to insulin resistance caused by inflammatory cytokines (64); however, the role of adipose tissue inflammation as a driver of insulin resistance is still debated. Furthermore, dietary ABA supplementation significantly reduced fasting insulin levels (65). While the benefits of ABA on glucose tolerance are clear, additional research into the impact and mechanisms of ABA in insulin resistance will enhance the functional knowledge on the actions of ABA in glucose metabolism.

\section{Microgram Amounts of ABA Improves Glucose Tolerance in Rats and in Humans without Increasing Insulinemia}

Despite the strong evidence demonstrating that $\mathrm{ABA}$ can stimulate insulin release from pancreatic $\beta$-cells in vitro (13), subsequent in vivo studies revealed that low-dose ABA improves glucose tolerance without increasing insulinemia. Rats and healthy humans undergoing an oral glucose tolerance test (OGTT) and treated with ABA, at a dose comprised between 0.5 and $1 \mu \mathrm{g} / \mathrm{kg}$ body weight, both show an improved glycemic profile and lower insulin levels compared with untreated controls (40). This unexpected result may have several, not necessarily mutually exclusive, reasons: (i) stimulation of glucose transport in GLUT4expressing cells by ABA may precede in time and/or exceed in extent the stimulation of insulin release; (ii) GLUT4-expressing cells may be more sensitive to the effect of ABA than $\beta$-pancreatic cells in vivo. In fact, the dose of ABA appears to be relevant for its effect on $\beta$-cells in vivo: at $50 \mathrm{mg} / \mathrm{kg}$, oral ABA alone (without glucose) increases insulinemia and reduces glycemia in rats (55). There is growing consensus within the scientific community that the prolonged stimulation of insulin release from $\beta$-cells under conditions of chronic hyperglycemia contributes to their eventual demise (66). For this reason, antidiabetic drugs capable of lowering glycemia without increasing insulinemia are highly desirable. 


\section{ABA Increases GLP-1p in Fasted Rats}

Besides lowering glycemia and increasing insulin release (only when administered at the high concentration of $50 \mathrm{mg} / \mathrm{kg}$ ), oral ABA determines the increase of GLP-1p, this effect having been tested only at high ABA concentration (55). The ABA-induced GLP-1p increase was measured both in the peripheral blood of rats pretreated with sitagliptin (an inhibitor of GLP-1 degrading enzymes), and in blood withdrawn from the portal vein of rats not pretreated with sitagliptin, clearly indicating that $\mathrm{ABA}$ stimulates also in vivo the release of GLP-1 from enteroendocrine cells, as it was demonstrated in an in vitro system. The increase in GLP-1p preceded the insulin increase (peaks at 20 and $40 \mathrm{~min}$, respectively); thus, a positive feedback loop might exists between ABA increasing GLP-1 (55), which in turn determines a further release of ABA from $\beta$-pancreatic cells (9), which potentiate insulin release (13). The effect of low concentrations of $\mathrm{ABA}$ on the in vivo GLP-1 release remains to be determined. Given that a low ABA concentration failed to induce an increase in insulinemia, despite its glycemia-lowering effect (40), the physiological relevance of the depicted loop at low, endogenous, $\mathrm{ABA}$ concentration is negligible. It remains unknown whether other cell types are able to respond to ABA by releasing GLP-1, and whether ABA can stimulate GLP-1 secretion also acting as a hormonal stimulus on the vascular side of L-cells, as it happens for glucose (67).

Currently, T2D treatments aimed at inhibiting GLP-1degrading enzymes (DPP4) or using GLP-1 mimetics are available (68). The fact that ABA stimulates GLP-1 release accounts for considering $\mathrm{ABA}$ as a new possible strategy to impact on the GLP-1 axis in T2D, alone or in combination with DPP4 inhibitor.

\section{ABA Reduces Adipose Tissue Inflammation}

Obesity and diabetes are characterized by a low-grade systemic chronic inflammation and insulin resistance. Hypertrophic adipocytes are insulin resistant and secrete more free fatty acids and TGs than they take up, leading to lipid deposition in peripheral tissues such as the liver and skeletal muscle. These cells also produce chemokines, such as MCP-1, which promote macrophage infiltration into the white adipose tissue. Bassaganya-Riera's team demonstrated that ABA treatment improves insulin sensitivity, decreases adipocyte hypertrophy, reduces macrophage infiltration into the white adipose tissue, and downregulates the levels of tumor necrosis alpha (TNF $\alpha)$ and MCP-1 in obese mice $(32,33)$. Later studies demonstrated that ABA, together with rosiglitazone, downregulates not only $\mathrm{F} 4 / 80^{+} \mathrm{CD} 11 \mathrm{~b}^{+}$pro-inflammatory macrophages in white adipose tissue (32), but also levels of MCP-1 (59). Interestingly, the downregulation of pro-inflammatory markers in ABA-treated mice could be explained by other findings, including the observation of upregulation of regulatory $\mathrm{T}$ (Treg) cells, together with a downregulation of blood CD11 $\mathrm{b}^{+}$ $\mathrm{CCR}^{+}$(the ligand of MCP-1) monocytes (65). Furthermore, data demonstrated that with the increase in $\mathrm{CD}^{+} \mathrm{T}$ cells there was a corresponding decrease in the percentages of $\mathrm{CD}^{+} \mathrm{T}$ cells in MLN following dietary ABA supplementation. Additionally, MLN CD $4^{+} \mathrm{IL}_{-10^{+}} \mathrm{T}$ cells and blood $\mathrm{CD} 4^{+} \mathrm{CD} 25^{+} \mathrm{Foxp}^{+}$Treg cells and $\mathrm{CD} 8^{+} \mathrm{IL}-10^{+} \mathrm{T}$ cells were significantly increased in ABAfed mice. These results together support the hypothesis that ABA reduces obesity-related systemic inflammation, especially in the adipose compartment.

The abovementioned findings suggested that the beneficial effects of ABA on glucose tolerance were mediated, in part, by its anti-inflammatory actions. Mechanistically, the reduction in adipocyte hypertrophy can prevent the hypertrophic adipocyteinduced hypoxia within adipose tissue. HIF1 $\alpha$ expression was identified to be downregulated by ABA treatment (34). Further, expression of HIF-inducible and -interacting genes, such as TLR4, JUN, and CDKN1A, were also identified to be downregulated by ABA treatment in splenocytes. Treatment with ABA also decreased TLR4 levels in blood and MLN (34). Examination of the HIF1 $\alpha$ pathway in more detail may unveil additional mechanisms of ABA-mediated downregulation of adipose tissue inflammation.

\section{Impaired Ability to Increase ABAp after Glucose Load in T2D and Gestational Diabetes (GDM)}

The increase of ABAp that occurs in healthy subjects after an oral glucose load (ABA response) (9) is impaired in patients with T2D and in women with GDM (56). GDM is a "reversible" diabetic condition that reverts to a normal glucose tolerant state after childbirth. Pointedly, normalization of glucose tolerance after childbirth was paralleled by restoration of both the ABAp response to oral glucose and normal fasting ABAp levels. Thus, impairment of the response of ABAp to hyperglycemia might be a commonality between T2D and GDM subjects, suggesting an important role for ABAp in maintaining normal glucose tolerance. Zocchi and colleagues also compared fasting ABAp before and after biliopancreatic diversion (BPD) in obese, but not diabetic subjects, and in obese T2D patients, in which BPD resulted in the resolution of diabetes. Compared to pre-BPD values, basal ABAp significantly increased 1 month after BPD in T2D as well as in NGT subjects, in parallel with a reduction of fasting plasma glucose, suggesting a beneficial effect of elevated ABAp on glycemic control (56). An intriguing hypothesis to explain the increase of ABAp after BPD is the stimulation of enteroendocrine cells by excess non-absorbed nutrients, resulting in an increased release of GLP-1 $(69,70)$, in turn stimulating ABA secretion from $\beta$-pancreatic cells.

The higher mean value and wider distribution of the fasting ABAp in the T2D subjects compared to the NGT controls (56) may reflect a pleiotropy of ABA-related dysfunctions in T2D, such as: (i) resistance to the glycemia-lowering effect of ABA, causing higher than normal basal ABAp levels, or, (ii) impairment of the molecular mechanisms regulating the increase of ABAp in response to hyperglycemia, causing ABAp levels to be in the normal range despite hyperglycemia. As opposed to what observed in T2D subjects, the fasting ABAp of the GDM subjects was consistently lower compared to the NGT controls, suggesting that insufficient ABA release in response to hyperglycemia may be the common mechanism of pathogenesis underlying $\mathrm{ABA}$ dysfunction in GDM. The fact that ABAp and its response to 
hyperglycemia are abnormal in T2D and GDM suggests a role for this dysregulation in the pathogenesis of these conditions.

\section{LANCL2 SIGNALING PATHWAY}

\section{ABA Binding by LANCL2: In Silico and In Vitro Evidence}

Direct evidence of specific and saturable ABA binding to recombinant, purified LANCL2 was obtained with two different LANCL2 recombinant proteins, a fusion protein with glutathione-S-transferase (LANCL2-GST) and LANCL2 cleaved from its GST tag, and through several different experimental approaches: binding with $\left[{ }^{3} \mathrm{H}\right]-\mathrm{ABA}$, scintillation proximity assays on immobilized LANCL2, dot blot experiments with biotinylated ABA (bio-ABA), and affinity chromatography of LANCL2 on immobilized ABA (71).

The relatively high Kd value for ABA of recombinant LANCL2 could be attributed to imperfect protein folding, as suggested by its fast precipitation after tag cleavage or to the requirement of posttranslational modifications to enhance its ABA-binding activity. Indeed, native LANCL2 is N-terminally myristoylated and interacts with membrane phosphatidylinositol phosphate(s), both modifications being required for its membrane association (28). Both ABA enantiomers, (S)- and (R)-ABA, completely displaced binding of $(\mathrm{R}, \mathrm{S})-\left[{ }^{3} \mathrm{H}\right] \mathrm{ABA}$ to LANCL2-GST, in agreement with the fact that both (S)- and (R)-ABA are biologically active on ABA-sensitive cells.

Parallel in silico studies, performed on a model structure of LANCL2, revealed a potential ABA-binding domain on LANCL2. This modeling prediction was validated experimentally using surface plasmon resonance (Figure 2) (72). Using that model, structure-based virtual screening was performed using compounds from NCI (National Cancer Institute) Diversity Set II, ChemBridge, ZINC natural products, and FDA-approved drugs databases. Lu et al. (73) identified several potential ligands using molecular docking. In order to validate the antiinflammatory efficacy of the top ranked compound (NSC61610) in the NCI Diversity Set II, a series of in vitro and preclinical efficacy studies were performed in mice with inflammatory bowel disease (IBD). The results in vivo demonstrated that the lead compound, NSC61610, engaged LANCL2 in an AC/cAMPdependent manner in vitro and ameliorated experimental IBD by downmodulating colonic inflammatory gene expression and favoring Treg cell responses (73). New derivatives and analogs of ABA and NSC61610 that bind to LANCL2 have been developed
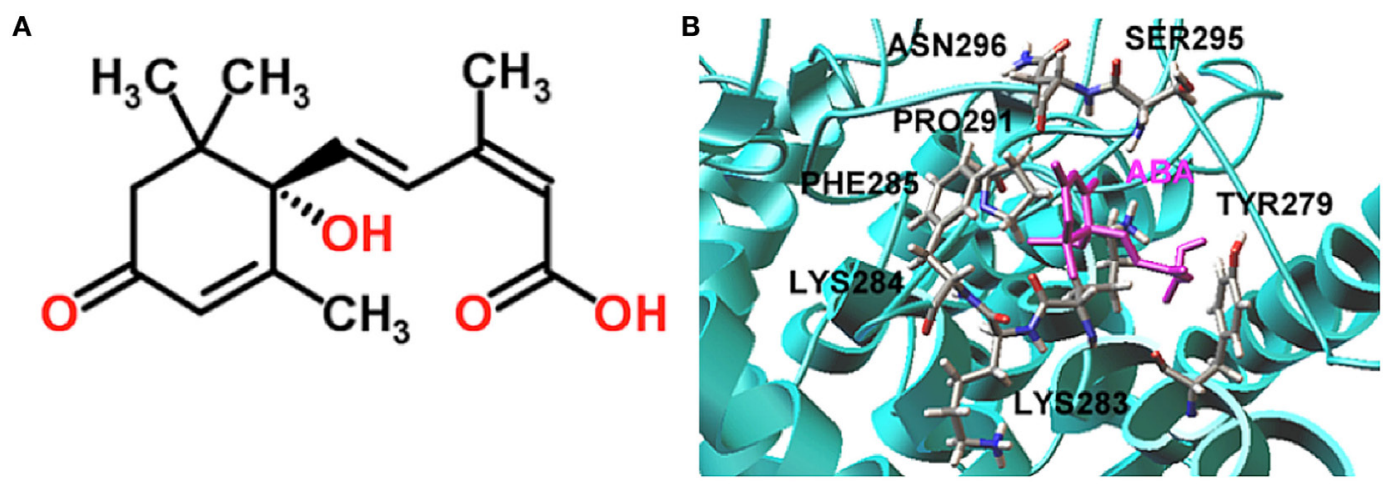

C

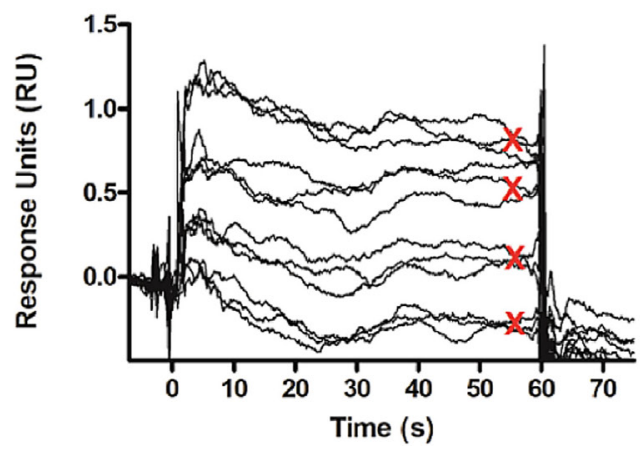

\section{Binding of abscisic acid to LANCL2}

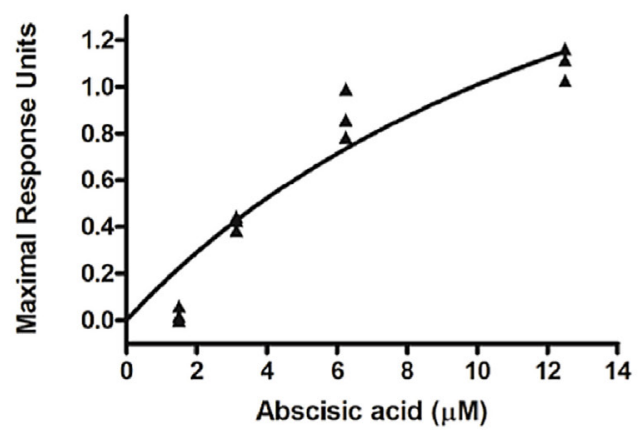

FIGURE 2 | Model structure of lanthionine synthetase C-like 2 (LANCL2) and putative ABA-binding site. (A) Chemical structure of abscisic acid (76). (B) Representative binding modes of the most stable docked orientation of ABA (shown in pink) with LANCL2. The amino acid residues surrounding ABA are indicated. (C) Surface plasmon resonance sensograms for the binding of varying concentrations of ABA (1, 3, 6, and 12 $\mu$ M) to immobilized LANCL2. (D) Plot of maximal resonance unit versus concentration of ABA. Steady-state dissociation constant was calculated to be $2.252 \mu \mathrm{M}$ utilizing a $1: 1$ binding model. Binding data first shown by Lu et al. (72). 
as potential, pharmaceutical activators of the LANCL2 pathway. BT-11 is being developed as a first-in-class oral small molecule therapeutic for Crohn's disease $(74,75)$. BT-11 is an orally active, locally acting small molecule compound that binds to LANCL2 in the gastrointestinal (GI) tract and decreases leukocytic infiltration, mucosal thickening, and epithelial erosion in the GI tract. These histological improvements correlate with decreased numbers of inflammatory $\mathrm{F} 4 / 80^{+} \mathrm{CD} 11 \mathrm{~b}^{+}$macrophages and effector $\mathrm{T}$ helper 1 (Th1) cells in the gut mucosa. BT-11 also increases the levels of FOXP3-expressing CD4+ Treg that express IL-10 in the gut lamina propria, spleen, and MLN. Gene expression analyses confirmed that oral administration of BT-11 upregulates the expression of IL-10 and LANCL2, and downregulates the expression of TNF $\alpha$ GI tissue of mice with experimental IBD. Furthermore, PK studies with BT-11 showed low plasma concentrations and elimination within hours after oral administration. Plasma concentrations were only slightly higher after oral administration of $500 \mathrm{mg} / \mathrm{kg}$ than they were after $80 \mathrm{mg} / \mathrm{kg}$ (sixfold dose difference). BT-11 concentrations in the intestine after the $80 \mathrm{mg} / \mathrm{kg}$ treatment were considerably higher than concentrations measured in plasma at the same time. In addition, BT-11 gave consistent $90 \%$ IBD reduction in three mouse models after both oral and rectal administration (8 mg/kg).

\section{Membrane Localization of LANCL2 and Mechanism of ABA Transport through the Plasma Membrane}

Lanthionine synthetase C-like 2 anchoring to the plasmamembrane occurs via N-terminal myristoylation and also via a basic phosphatidylinositol phosphate-binding site (28). LANCL2 is not a transmembrane protein, as it is detached from the erythrocyte membrane by relatively mild chemical treatments, in the absence of detergents (77). Thus, LANCL2 localization implies that ABA binding may occur intracellularly, raising the issue of how ABA gains access to its intracellular receptor. Protonated ABA can diffuse through the lipid bilayer and this passive diffusion is believed to drive ABA out of the xylem sap and into plant cell tissues, although transmembrane, ATP-dependent ABA transporters are also present in plant cells (78). The $\mathrm{pKa}$ of ABA is 4.7; thus at $\mathrm{pH}$ values typical of extra- and intracellular fluids in animals (approximately 7.5 ) $<0.2 \%$ of ABA is protonated and $\mathrm{ABA}$ is mostly membrane impermeable. The protein responsible for $\mathrm{ABA}$ transport was identified as the anion transporter Band 3 in human erythrocytes (RBC), on the basis of several lines of evidence: (i) chloride ions compete with ABA for influx into RBC; (ii) the specific Band 3 inhibitor DIDS inhibits influx of ABA; (iii) Band 3 binds bio-ABA and bio-ABA can be displaced by excess $\mathrm{ABA}$, indicating a specific interaction between $\mathrm{ABA}$ and the transporter; (iv) proteoliposomes reconstituted with purified Band 3 are able to transport ABA and sulfate (77). The erythrocyte anion transporter Band 3 (also called AE1) is a member of a protein family of anion transporters that includes AE2 and AE3. While AE1 is expressed only on erythrocytes, AE2 and AE3 are expressed in nucleated cells. In line with what was observed on Band 3, AE2 has been recently shown to mediate $\mathrm{ABA}$ transport in human nucleated cells and to allow the functional effect of extracellular ABA in keratinocytes (79).

ABA transport across AE1 and AE2 is bidirectional, allowing the free flux of ABA along its concentration gradient. The non-concentrative nature of the transporter allows circulating or paracrinally produced $\mathrm{ABA}$ to exert its functional effect on target cells: ABA-releasing cells can export ABA to bystander cells or into the bloodstream and $\mathrm{ABAp}$ can reach cells distant from the ABA-producing ones. Indeed, autocrine $(9-11,16,17)$, paracrine $(12,15-17)$, and endocrine $(13,40,55)$ effects of ABA have been described.

\section{ABA/LANCL2 Signaling in Cells Involved in Glucose Homeostasis: Adipocytes, Myocytes, and Hepatocytes}

The first evidence indicating that ABA, similar to insulin, triggers the Ser phosphorylation of protein kinase Akt, came from experiments on adipocytes, as already described above (9). Later, by the use of LY294002, a PI3K specific inhibitor, the PI3K/Akt signaling pathway was demonstrated to mediate the ABAinduced activation of NADPH oxidase and of ROS generation, in the murine macrophage cell line RAW264.7 (11) and of glucose transport in rodent 3T3-L1 adipocytes (80). More recently, Zeng et al. (62) demonstrated that LANCL2 positively regulates Akt phosphorylation in four different liver cell lines. This regulation does not occur through the canonical-insulin signaling pathway, since LANCL2 knockdown affected neither the level of insulin receptor nor its phosphorylation. Instead, LANCL2 was found to physically interact with Akt. Through in vitro kinase assays with immunoprecipitated mTORC2 (one of the kinases having Akt as substrate) and recombinant Akt, in the absence or presence of purified LANCL2, Zeng et al. (62) demonstrated that LANCL2 regulates Akt phosphorylation by mTORC2. In addition, LANCL2 facilitates the phosphorylation of SGK1, and in turn of NDRG1, by mTORC2. Whether LANCL2 physically interacts with SGK1, as a common mechanism with Akt, in order to facilitate its phosphorylation by $\mathrm{mTORC} 2$, remains to be determined. Given the established role of $\mathrm{ABA}$ and of Akt in glycemia regulation, further investigation on the molecular interaction between LANCL2 and Akt in cells other than liver cells are needed.

\section{ABA/LANCL2 Signaling in Immune Modulation}

ABA expands human uncommitted HP in vitro: 24 -h priming with low micromolar ABA prior to seeding of the cells in a growth factor-enriched medium stimulates colony output from human cord blood-derived colony forming cells (CFC) and also from purified $\mathrm{CD}_{3} 4^{+}$cells, the subpopulation of HP containing the most immature progenitor cells. ABA stimulates the proliferative potential of the single $\mathrm{CFC}$, increasing cell number in first generation colonies, and also stimulates the self-renewal of clonogenic $\mathrm{HP}$, increasing the number of second and third generation colonies and resulting in a 1-log higher cell expansion factor in the ABA-treated cells compared with controls (15). 
The stimulatory effect of ABA on HP proliferation is mediated by an increase of the $\mathrm{Ca}_{\text {cyt }}^{2+}$, which is dependent upon a signaling pathway sequentially involving a PTX-sensitive Gi, stimulation of the ADPRC activity of CD38 and increase of intracellular cADPR (15). The ABA-induced increase of the $\mathrm{Ca}_{\text {cyt }}^{2+}$ exerts transcriptional effects on HP via the nuclear translocation of $\mathrm{NF}-\mathrm{kB}$, stimulating transcription and release of several cytokines and growth factors, including VEGF, IL-8, IL-1 $\beta$, IL-9, Fas ligand, GRO, and RANTES. VEGF and IL-8 are partly responsible for the autocrine stimulation of cell proliferation induced by ABA on HP, since blocking antibodies against these cytokines reduce the ABA-mediated increase of colony output. Interestingly, IL-8 stimulates release of ABA from MSCs (14).

In the hemopoietic niche, MSCs provide physical and trophic support to HP, and function as immunomodulators, preventing lymphocyte activation, which negatively affects hemopoiesis. Indeed, MSC co-transplantation is a routine practice in allogeneic hematopoietic stem cell transplantation in some hematological centers (81). Several cytokines released by activated allogeneic lymphocytes, TNF- $\alpha$, RANTES, and IL- 8 , induce the release of ABA from human MSCs; ABA in turn stimulates MSC proliferation and the release of hemopoietic growth factors, including IL-6, IL-8, oncostatin M, MIP-1d, and GRO (14). Presence of an anti-ABA monoclonal antibody prevents the growth-stimulatory effect of the coculture with MSC on second generation colony output from $\mathrm{CD}_{3} 4^{+}$cells (15). Thus, a positive feedback mechanism can be envisioned between MSC and HP in the hemopoietic niche, where ABA released by MSC behaves as an autocrine stimulator of stromal function and as a paracrine growth factor for HP (Figure 3).

$\mathrm{ABA}$ is also released by activated granulocytes (see Figure 1), eliciting the intriguing hypothesis that ABA may function as either a "danger" signal during infection or inflammation or a regulatory molecule for maintaining immune homeostasis. Such series of events are intimately linked to activation of LANCL2, which triggers a decrease in $\mathrm{F} 4 / 80^{+} \mathrm{CD} 11 \mathrm{~b}^{+}$macrophages, plus an increase in circulating Treg cells after dietary ABA treatment (65). The activation of LANCL2 also triggers a release of IL-10 in $\mathrm{CXCR}^{+}$macrophages (Figure 3). Linked to these findings, Bassaganya-Riera et al. (34) published a study demonstrating that dietary ABA supplementation reduced levels of TNF $\alpha$ while upregulating Glut4 in the spleen during LPS challenge of mice. These results have been validated by another study in which activation of LANCL2 led to a decrease in TNF $\alpha$, MCP-1, and IFN $\gamma$, as well as a reduction in Th1 $\mathrm{CD}^{+} \mathrm{T}$ cells and an increase in Treg cells by the novel LANCL2 ligand, BT-11 (75). BT-11 binds to LANCL2, is orally active, has demonstrated efficacy in three validated mouse models of IBD at $8 \mathrm{mg} / \mathrm{kg}$, and has a benign safety profile based on single dose, multiple dose and DRF studies in rats up to $1,000 \mathrm{mg} / \mathrm{kg}$ (74). Thus, activation of LANCL2 acts as an internal sensor activated by environmental dysregulation (e.g., inflammatory, dietary, or metabolic signals) that activates

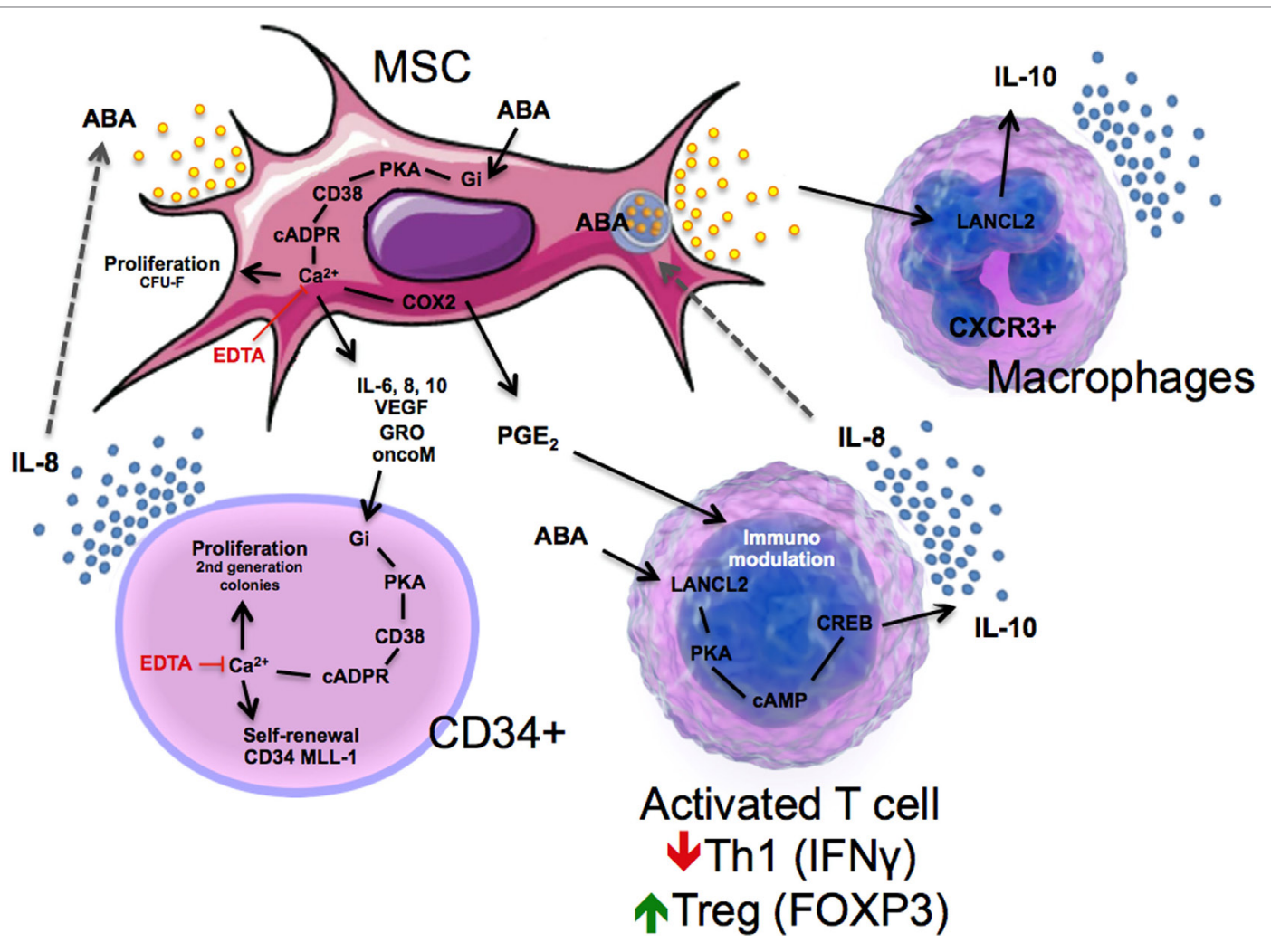

FIGURE 3 | Schematic representation of immune modulatory actions of ABA in mesenchymal stem cell (MSC), CD34+ cells, T cells, and macrophages through lanthionine synthetase C-like 2 (LANCL2)-dependent mechanisms. 
cellular and molecular pathways involved in homeostatic control of immunity and metabolism.

\section{CONCLUSION}

ABA and its proposed receptor LANCL2 are emerging as new important players in the physiology and in the dysfunction of mammalian glucose homeostasis and immunoregulation. Over 28.3 million Americans have T2D and over $40.1 \%$ of middle-aged adults have prediabetes, a disease that has reached pandemic proportions in the U.S. Diabetes is the seventh leading cause of death worldwide, mainly due to its cardiovascular sequel. While T2D is an irreversible condition, prediabetes is not. Only less than $4 \%$ of prediabetic subjects receive pharmacologic treatment, as they do not yet classify as "diabetic." Prediabetic or high-risk individuals, such as those afflicted by excess body weight, high blood lipids and hypertension, all hallmarks of the metabolic syndrome, are advised to follow dietary and lifestyle guidelines, which have a very low rate of adherence. Consequently, many of these subjects will become diabetic. This dramatic forecast calls for new and aggressive strategies to tackle the expanding incidence of diabetes pandemic before it becomes an even greater societal burden.

Dietary low-dose $A B A$ improves glucose tolerance in healthy subjects without increasing insulinemia and oral ABA improves glucose tolerance in diabetic mice. Furthermore, the increase of ABAp that occurs after an OGTT is impaired in patients with T2D and in women with GDM. The mechanism of action of low-dose ABA in vivo is likely mediated by its stimulation of GLUT4-mediated glucose uptake, rather than insulin release, as insulinemia is in fact reduced by ABA treatment. Dietary ABA administration in the form of foods or beverages can be proposed as a new intervention, capable of improving glucose tolerance, while at the same time sparing the $\beta$-cell reservoir. ABA is both an endogenous and dietary LANCL2-activating compound. Nanomolar plasma concentrations, in the physiological range and attainable by dietary intake of a dose of approximately $1 \mu \mathrm{g} / \mathrm{kg}$ body weight, are effective on glycemic control. These two facts together allow its safe use to maintain healthy blood glucose levels and to prevent diabetes. In addition, low-dose ABA does not increase insulin release and this may prove advantageous in diabetic, prediabetic, and metabolic syndrome subjects, who are deficient in and/or resistant to insulin. By reducing the chronic stimulation by hyperglycemia of $\beta$-cells to release insulin, lowdose $\mathrm{ABA}$ administration should improve survival and function of these cells.

Identifying other LANCL2-activating compounds may also prove a successful strategy, in view of the multiple anti-diabetic, anti-inflammatory, and immunoregulatory effects that they might trigger. Indeed, LANCL2 can: (i) facilitate Akt phosphorylation and increase GLUT4-mediated glucose uptake, an Akt-dependent mechanism; (ii) mediate the ABA-stimulated GLP-1 release from L cells; and (ii) exert immunoregulatory and anti-inflammatory actions in the gut, blood vessels, and adipose tissue. The potential role of LANCL2 as a new drug target in diabetes has already been suggested (82) and efforts at discovering LANCL2-targeting drugs are underway. Furthermore, the ABA-based technology through the LANCL2 pathway to fight inflammation and diabetes has been patented, through method of utilization as well as composition of matter claims, by Bassaganya-Riera et al.

In summary, the data reviewed in this manuscript demonstrates that dietary or endogenously produced ABA is a new human signaling molecule that regulates responses to environmental challenges (i.e., metabolic, nutritional, inflammatory, and immunological), and it is implicated in glycemic control through a LANCL2-dependent mechanism. ABA not only regulates blood glucose levels and prevents the onset of T2D in mice and rats, but more importantly microgram amounts of dietary ABA are sufficient to improve glycemic controls in humans. Given the extensive results demonstrating a role for $\mathrm{ABA}$ in regulating glycemic control, ABA-based interventions have the potential to improve glycemic control in millions of people afflicted by prediabetes, diabetes, and metabolic syndrome worldwide.

\section{METHODS}

This comprehensive and up-to-date review summarizes the in vitro, preclinical, mechanistic, and clinical results obtained over the past 15 years by the two leading groups involved in the study of the metabolic, nutritional, and immunological actions of ABA. Only two such reviews exist on this subject $(83,84)$; with the new review, the authors wish to implement the literature with their most recent results, focusing on the arguably most clinically relevant role of $\mathrm{ABA}$ as a new human hormone involved in the control of glycemia. The authors kept a balance between independently published papers and papers published by the authors. The scientific literature summarized in the review has been published over the years 2001-2017 in peer-reviewed international journals, including Proc Natl Acad Sci U S A, J Biol Chem, FASEB J, Stem Cells, Clin Nutr, J Nutr Biochem, J Cell Physiol, and PloS One, among others.

\section{AUTHOR CONTRIBUTIONS}

$\mathrm{EZ}, \mathrm{JR}, \mathrm{AL}$, and $\mathrm{RH}$ designed the architecture of the review. EZ, SB, NP, RH, JR, AC, NT-J, VZ-R, LS, and AE performed the searches for the review. EZ, SB, RH, AC, JR, and AE wrote and edited the manuscript.

\section{FUNDING}

This paper was supported by NIH/NIDDK grant R43DK109836. This work was also supported in part by the Italian Ministry of Education, University and Scientific Research (grants PRIN \#2007BZ4RX3_005 and FIRB 2012\#RBFR1299K0_002), by the Fondazione CARIGE, by the Compagnia di S. Paolo di Torino (grant \#2012-ID ROL 316), by the University of Genova (PRA2012), and by Regione Liguria. 


\section{REFERENCES}

1. Kato-Noguchi H, Tanaka Y, Murakami T, Yamamura S, Fujihara S. Isolation and identification of an allelopathic substance from peel of Citrus junos. Phytochemistry (2002) 61(7):849-53. doi:10.1016/ S0031-9422(02)00382-5

2. Milborrow BV. The pathway of biosynthesis of abscisic acid in vascular plants: a review of the present state of knowledge of ABA biosynthesis. J Exp Bot (2001) 52(359):1145-64. doi:10.1093/jexbot/52.359.1145

3. Gomez-Cadenas A, Vives V, Zandalinas SI, Manzi M, Sanchez-Perez AM, Perez-Clemente RM, et al. Abscisic acid: a versatile phytohormone in plant signaling and beyond. Curr Protein Pept Sci (2015) 16(5):413-34. doi:10.2174 /1389203716666150330130102

4. Raghavendra AS, Gonugunta VK, Christmann A, Grill E. ABA perception and signalling. Trends Plant Sci (2010) 15(7):395-401. doi:10.1016/j. tplants.2010.04.006

5. Zocchi E, Carpaneto A, Cerrano C, Bavestrello G, Giovine M, Bruzzone S, et al. The temperature-signaling cascade in sponges involves a heat-gated cation channel, abscisic acid, and cyclic ADP-ribose. Proc Natl Acad Sci U S A (2001) 98(26):14859-64. doi:10.1073/pnas.261448698

6. Zocchi E, Basile G, Cerrano C, Bavestrello G, Giovine M, Bruzzone S, et al. ABA- and CADPR-mediated effects on respiration and filtration downstream of the temperature-signaling cascade in sponges. JCell Sci (2003) $116(\mathrm{Pt}$ 4):629-36. doi: $10.1242 /$ jcs.00277

7. Puce S, Basile G, Bavestrello G, Bruzzone S, Cerrano C, Giovine M, et al. Abscisic acid signaling through cyclic ADP-ribose in hydroid regeneration. J Biol Chem (2004) 279(38):39783-8. doi:10.1074/jbc.M405348200

8. Le Page-Degivry MT, Bidard JN, Rouvier E, Bulard C, Lazdunski M. Presence of abscisic acid, a phytohormone, in the mammalian brain. Proc Natl Acad Sci U S A (1986) 83(4):1155-8. doi:10.1073/pnas.83.4.1155

9. Bruzzone S, Ameri P, Briatore L, Mannino E, Basile G, Andraghetti G, et al. The plant hormone abscisic acid increases in human plasma after hyperglycemia and stimulates glucose consumption by adipocytes and myoblasts. FASEB $J(2012)$ 26(3):1251-60. doi:10.1096/f.11-190140

10. Bruzzone S, Moreschi I, Usai C, Guida L, Damonte G, Salis A, et al. Abscisic acid is an endogenous cytokine in human granulocytes with cyclic ADPribose as second messenger. Proc Natl Acad Sci U S A (2007) 104(14):5759-64. doi:10.1073/pnas.0609379104

11. Magnone M, Sturla L, Jacchetti E, Scarfi S, Bruzzone S, Usai C, et al. Autocrine abscisic acid plays a key role in quartz-induced macrophage activation. FASEB $J$ (2012) 26(3):1261-71. doi:10.1096/fi.11-187351

12. Magnone M, Bruzzone S, Guida L, Damonte G, Millo E, Scarfi S, et al. Abscisic acid released by human monocytes activates monocytes and vascular smooth muscle cell responses involved in atherogenesis. J Biol Chem (2009) 284(26):17808-18. doi:10.1074/jbc.M809546200

13. Bruzzone S, Bodrato N, Usai C, Guida L, Moreschi I, Nano R, et al. Abscisic acid is an endogenous stimulator of insulin release from human pancreatic islets with cyclic ADP ribose as second messenger. J Biol Chem (2008) 283(47):32188-97. doi:10.1074/jbc.M802603200

14. Scarfi S, Ferraris C, Fruscione F, Fresia C, Guida L, Bruzzone S, et al. Cyclic ADP-ribose-mediated expansion and stimulation of human mesenchymal stem cells by the plant hormone abscisic acid. Stem Cells (2008) 26(11):2855-64. doi:10.1634/stemcells.2008-0488

15. Scarfi S, Fresia C, Ferraris C, Bruzzone S, Fruscione F, Usai C, et al. The plant hormone abscisic acid stimulates the proliferation of human hemopoietic progenitors through the second messenger cyclic ADP-ribose. Stem Cells (2009) 27(10):2469-77. doi:10.1002/stem.173

16. Bruzzone S, Basile G, Mannino E, Sturla L, Magnone M, Grozio A, et al. Autocrine abscisic acid mediates the UV-B-induced inflammatory response in human granulocytes and keratinocytes. J Cell Physiol (2012) 227(6):2502-10. doi:10.1002/jcp. 22987

17. Bruzzone S, Battaglia F, Mannino E, Parodi A, Fruscione F, Basile G, et al. Abscisic acid ameliorates the systemic sclerosis fibroblast phenotype in vitro. Biochem Biophys Res Commun (2012) 422(1):70-4. doi:10.1016/j. bbrc.2012.04.107

18. Leckie CP, McAinsh MR, Allen GJ, Sanders D, Hetherington AM. Abscisic acid-induced stomatal closure mediated by cyclic ADP-ribose. Proc Natl Acad Sci U S A (1998) 95(26):15837-42. doi:10.1073/pnas.95.26.15837
19. Wu Y, Kuzma J, Marechal E, Graeff R, Lee HC, Foster R, et al. Abscisic acid signaling through cyclic ADP-ribose in plants. Science (1997) 278(5346):2126-30. doi:10.1126/science.278.5346.2126

20. Ferrero E, Lo Buono N, Horenstein AL, Funaro A, Malavasi F. The ADP-ribosyl cyclases - the current evolutionary state of the ARCs. Front Biosci (Landmark Ed) (2014) 19:986-1002. doi:10.2741/4262

21. Sanchez JP, Duque P, Chua NH. ABA activates ADPR cyclase and cADPR induces a subset of ABA-responsive genes in Arabidopsis. Plant $J$ (2004) 38(3):381-95. doi:10.1111/j.1365-313X.2004.02055.x

22. Sturla L, Fresia C, Guida L, Bruzzone S, Scarfi S, Usai C, et al. LANCL2 is necessary for abscisic acid binding and signaling in human granulocytes and in rat insulinoma cells. J Biol Chem (2009) 284(41):28045-57. doi:10.1074/ jbc.M109.035329

23. Johnston CA, Temple BR, Chen JG, Gao Y, Moriyama EN, Jones AM, et al. Comment on "A G protein coupled receptor is a plasma membrane receptor for the plant hormone abscisic acid". Science (2007) 318(5852):914; author reply. doi:10.1126/science. 1143230

24. Bauer H, Mayer H, Marchler-Bauer A, Salzer U, Prohaska R. Characterization of $\mathrm{p} 40 /$ GPR69A as a peripheral membrane protein related to the lantibiotic synthetase component C. Biochem Biophys Res Commun (2000) 275(1):69-74. doi:10.1006/bbrc. 2000.3260

25. Sahl HG, Bierbaum G. Lantibiotics: biosynthesis and biological activities of uniquely modified peptides from gram-positive bacteria. Аnnu Rev Microbiol (1998) 52:41-79. doi:10.1146/annurev.micro.52.1.41

26. Katoh M, Katoh M. Identification and characterization of human ZPBPlike gene in silico. Int J Mol Med (2003) 12(3):399-404. doi:10.3892/ ijmm.12.3.399

27. Mayer H, Bauer H, Prohaska R. Organization and chromosomal localization of the human and mouse genes coding for LanC-like protein 1 (LANCL1). Cytogenet Cell Genet (2001) 93(1-2):100-4. doi:10.1159/000056958

28. Landlinger C, Salzer U, Prohaska R. Myristoylation of human LanC-like protein 2 (LANCL2) is essential for the interaction with the plasma membrane and the increase in cellular sensitivity to adriamycin. Biochim Biophys Acta (2006) 1758(11):1759-67. doi:10.1016/j.bbamem.2006.07.018

29. Fresia C, Vigliarolo T, Guida L, Booz V, Bruzzone S, Sturla L, et al. G-protein coupling and nuclear translocation of the human abscisic acid receptor LANCL2. Sci Rep (2016) 6:26658. doi:10.1038/srep26658

30. Takasawa S, Nata K, Yonekura H, Okamoto H. Cyclic ADP-ribose in insulin secretion from pancreatic beta cells. Science (1993) 259(5093):370-3. doi:10.1126/science.8420005

31. Charles MA, Fanska R, Schmid FG, Forsham PH, Grodsky GM. Adenosine 3'5'-monophosphate in pancreatic islets: glucose-induced insulin release. Science (1973) 179(4073):569-71. doi:10.1126/science.179.4073.569

32. Guri AJ, Hontecillas R, Si H, Liu D, Bassaganya-Riera J. Dietary abscisic acid ameliorates glucose tolerance and obesity-related inflammation in $\mathrm{db} /$ db mice fed high-fat diets. Clin Nutr (2007) 26(1):107-16. doi:10.1016/j. clnu.2006.07.008

33. Guri AJ, Hontecillas R, Ferrer G, Casagran O, Wankhade U, Noble AM, et al. Loss of PPAR gamma in immune cells impairs the ability of abscisic acid to improve insulin sensitivity by suppressing monocyte chemoattractant protein-1 expression and macrophage infiltration into white adipose tissue. J Nutr Biochem (2008) 19(4):216-28. doi:10.1016/j.jnutbio.2007.02.010

34. Bassaganya-Riera J, Guri AJ, Lu P, Climent M, Carbo A, Sobral BW, et al. Abscisic acid regulates inflammation via ligand-binding domain-independent activation of peroxisome proliferator-activated receptor gamma. J Biol Chem (2011) 286(4):2504-16. doi:10.1074/jbc.M110.160077

35. Tennant DR, Davidson J, Day AJ. Phytonutrient intakes in relation to European fruit and vegetable consumption patterns observed in different food surveys. Br J Nutr (2014) 112(7):1214-25. doi:10.1017/S0007114514001950

36. Murphy MM, Barraj LM, Herman D, Bi X, Cheatham R, Randolph RK. Phytonutrient intake by adults in the United States in relation to fruit and vegetable consumption. J Acad Nutr Diet (2012) 112(2):222-9. doi:10.1016/j. jada.2011.08.044

37. Cassidy A, O'Reilly EJ, Kay C, Sampson L, Franz M, Forman JP, et al. Habitual intake of flavonoid subclasses and incident hypertension in adults. Am J Clin Nutr (2011) 93(2):338-47. doi:10.3945/ajcn.110.006783

38. Wang L, Lee IM, Zhang SM, Blumberg JB, Buring JE, Sesso HD. Dietary intake of selected flavonols, flavones, and flavonoid-rich foods and risk of 
cancer in middle-aged and older women. Am J Clin Nutr (2009) 89(3):905-12. doi:10.3945/ajen.2008.26913

39. Rehm CD, Penalvo JL, Afshin A, Mozaffarian D. Dietary intake among US adults, 1999-2012. JAMA (2016) 315(23):2542-53. doi:10.1001/ jama.2016.7491

40. Magnone M, Ameri P, Salis A, Andraghetti G, Emionite L, Murialdo G, et al. Microgram amounts of abscisic acid in fruit extracts improve glucose tolerance and reduce insulinemia in rats and in humans. FASEB $J$ (2015) 29(12):4783-93. doi:10.1096/f.15-277731

41. Adato I, Gazit S, Blumenfeld A. Relationship between changes in abscisic acid and ethylene production during ripening of avocado fruits. Aust J Plant Physiol (1976) 3(4):555-8. doi:10.1071/PP9760555

42. Goldschmidt EE, Goren R, Even-Chen Z, Bittner S. Increase in free and bound abscisic acid during natural and ethylene-induced senescence of citrus fruit peel. Plant Physiol (1973) 51(5):879-82. doi:10.1104/pp.51.5.879

43. Serrano M, Martínez-Madrid MC, Riquelme F, Romojaro F. Endogenous levels of polyamines and abscisic acid in pepper fruits during growth and ripening. Physiol Plant (1995) 95(1):73-6. doi:10.1111/j.1399-3054.1995.tb00810.x

44. Kojima K, Shiozaki K, Koshita Y, Ishida M. Changes of endogenous levels of ABA, IAA and GA-like substances in fruitlets of parthenocarpic persimmon. J Jpn Soc Hortic Sci (1999) 68(2):242-7. doi:10.2503/jjshs.68.242

45. Goldbach H, Michael G. Abscisic acid content of barley grains during ripening as affected by temperature and variety. Alliance Crop Soil Environ Sci Soc (1976) 16(6):797-9. doi:10.2135/cropsci1976.0011183X001600060015x

46. Holappa LD, Blum U. Effects of exogenously applied ferulic acid, a potential allelopathic compound, on leaf growth, water utilization, and endogenous abscisic acid levels of tomato, cucumber, and bean. JChem Ecol (1991) 17(5):865-86. doi:10.1007/BF01395596

47. Cheikh N, Jones RJ. Disruption of maize kernel growth and development by heat stress (role of cytokinin/abscisic acid balance). Plant Physiol (1994) 106(1):45-51. doi:10.1104/pp.106.1.45

48. Browning G. Endogenous cis,trans-abscisic acid and pea seed development: evidence for a role in seed growth from changes induced by temperature. J Exp Bot (1980) 31(1):185-97. doi:10.1093/jxb/31.1.185

49. Simko I, McMurry S, Yang HM, Manschot A, Davies PJ, Ewing EE. Evidence from polygene mapping for a causal relationship between potato tuber dormancy and abscisic acid content. Plant Physiol (1997) 115(4):1453-9. doi:10.1104/pp.115.4.1453

50. Schussler JR, Brenner ML, Brun WA. Relationship of endogenous abscisic acid to sucrose level and seed growth rate of soybeans. Plant Physiol (1991) 96(4):1308-13. doi:10.1104/pp.96.4.1308

51. King RW. Abscisic acid in developing wheat grains and its relationship to grain growth and maturation. Planta (1976) 132(1):43-51. doi:10.1007/BF00390329

52. Ulaszewska MM, Trost K, Stanstrup J, Tuohy KM, Franceschi P, Chong MF, et al. Urinary metabolomic profiling to identify biomarkers of a flavonoid-rich and flavonoid-poor fruits and vegetables diet in adults: the FLAVURS trial. Metabolomics (2016) 12:32. doi:10.1007/s11306-015-0935-z

53. Wallace TC, Blumberg JB, Johnson EJ, Shao A. Dietary bioactives: establishing a scientific framework for recommended intakes. Adv Nutr (2015) 6(1):1-4. doi:10.3945/an.114.007294

54. Holst JJ, Vilsboll T, Deacon CF. The incretin system and its role in type 2 diabetes mellitus. Mol Cell Endocrinol (2009) 297(1-2):127-36. doi:10.1016/j. mce.2008.08.012

55. Bruzzone S, Magnone M, Mannino E, Sociali G, Sturla L, Fresia C, et al. Abscisic acid stimulates glucagon-like peptide-1 secretion from L-cells and its oral administration increases plasma glucagon-like peptide-1 levels in rats. PLoS One (2015) 10(10):e0140588. doi:10.1371/journal.pone.0140588

56. Ameri P, Bruzzone S, Mannino E, Sociali G, Andraghetti G, Salis A, et al. Impaired increase of plasma abscisic acid in response to oral glucose load in type 2 diabetes and in gestational diabetes. PLoS One (2015) 10(2):e0115992. doi:10.1371/journal.pone.0115992

57. Vilsboll T, Krarup T, Sonne J, Madsbad S, Volund A, Juul AG, et al. Incretin secretion in relation to meal size and body weight in healthy subjects and people with type 1 and type 2 diabetes mellitus. J Clin Endocrinol Metab (2003) 88(6):2706-13. doi:10.1210/jc.2002-021873

58. Sarraju A, Kim SH, Knowles JW. Cardiometabolic effects of glucagon-like peptide-1 agonists. Curr Atheroscler Rep (2016) 18(2):7. doi:10.1007/ s11883-016-0558-5
59. Guri AJ, Misyak SA, Hontecillas R, Hasty A, Liu D, Si H, et al. Abscisic acid ameliorates atherosclerosis by suppressing macrophage and CD4+ T cell recruitment into the aortic wall. J Nutr Biochem (2010) 21(12):1178-85. doi:10.1016/j.jnutbio.2009.10.003

60. Abel ED, Peroni O, Kim JK, Kim YB, Boss O, Hadro E, et al. Adipose-selective targeting of the GLUT4 gene impairs insulin action in muscle and liver. Nature (2001) 409(6821):729-33. doi:10.1038/35055575

61. Yang Q, Graham TE, Mody N, Preitner F, Peroni OD, Zabolotny JM, et al. Serum retinol binding protein 4 contributes to insulin resistance in obesity and type 2 diabetes. Nature (2005) 436(7049):356-62. doi:10.1038/ nature 03711

62. Zeng M, van der Donk WA, Chen J. Lanthionine synthetase C-like protein 2 (LanCL2) is a novel regulator of Akt. Mol Biol Cell (2014) 25(24):3954-61. doi:10.1091/mbc.E14-01-0004

63. Sato M, Dehvari N, Oberg AI, Dallner OS, Sandstrom AL, Olsen JM, et al. Improving type 2 diabetes through a distinct adrenergic signaling pathway involving mTORC2 that mediates glucose uptake in skeletal muscle. Diabetes (2014) 63(12):4115-29. doi:10.2337/db13-1860

64. Wieser V, Moschen AR, Tilg H. Inflammation, cytokines and insulin resistance: a clinical perspective. Arch Immunol Ther Exp (Warsz) (2013) 61(2):119-25. doi:10.1007/s00005-012-0210-1

65. Guri AJ, Hontecillas R, Bassaganya-Riera J. Abscisic acid synergizes with rosiglitazone to improve glucose tolerance and down-modulate macrophage accumulation in adipose tissue: possible action of the cAMP/ PKA/PPAR gamma axis. Clin Nutr (2010) 29(5):646-53. doi:10.1016/j. clnu.2010.02.003

66. Muoio DM, Newgard CB. Mechanisms of disease: molecular and metabolic mechanisms of insulin resistance and beta-cell failure in type 2 diabetes. Nat Rev Mol Cell Biol (2008) 9(3):193-205. doi:10.1038/nrm2327

67. Ezcurra M, Reimann F, Gribble FM, Emery E. Molecular mechanisms of incretin hormone secretion. Curr Opin Pharmacol (2013) 13(6):922-7. doi:10.1016/j.coph.2013.08.013

68. Sandoval DA, D'Alessio DA. Physiology of proglucagon peptides: role of glucagon and GLP-1 in health and disease. Physiol Rev (2015) 95(2):513-48. doi:10.1152/physrev.00013.2014

69. Valverde I, Puente J, Martin-Duce A, Molina L, Lozano O, Sancho V, et al. Changes in glucagon-like peptide-1 (GLP-1) secretion after biliopancreatic diversion or vertical banded gastroplasty in obese subjects. Obes Surg (2005) 15(3):387-97. doi:10.1381/0960892053576613

70. Lugari R, Dei Cas A, Ugolotti D, Barilli AL, Camellini C, Ganzerla GC, et al. Glucagon-like peptide 1 (GLP-1) secretion and plasma dipeptidyl peptidase IV (DPP-IV) activity in morbidly obese patients undergoing biliopancreatic diversion. Horm Metab Res (2004) 36(2):111-5. doi:10.1055/s-2004-814222

71. Sturla L, Fresia C, Guida L, Grozio A, Vigliarolo T, Mannino E, et al. Binding of abscisic acid to human LANCL2. Biochem Biophys Res Commun (2011) 415(2):390-5. doi:10.1016/j.bbrc.2011.10.079

72. Lu P, Bevan DR, Lewis SN, Hontecillas R, Bassaganya-Riera J. Molecular modeling of lanthionine synthetase component C-like protein 2: a potential target for the discovery of novel type 2 diabetes prophylactics and therapeutics. J Mol Model (2011) 17(3):543-53. doi:10.1007/s00894-010-0748-y

73. Lu P, Hontecillas R, Horne WT, Carbo A, Viladomiu M, Pedragosa M, et al. Computational modeling-based discovery of novel classes of anti-inflammatory drugs that target lanthionine synthetase C-like protein 2. PLoS One (2012) 7(4):e34643. doi:10.1371/journal.pone.0034643

74. Bissel P, Boes K, Hinckley J, Jortner BS, Magnin-Bissel G, Werre SR, et al. Exploratory studies with BT-11: a proposed orally active therapeutic for Crohn's disease. Int J Toxicol (2016) 35(5):521-9. doi:10.1177/1091581816646356

75. Carbo A, Gandour RD, Hontecillas R, Philipson N, Uren A, Bassaganya-Riera J. An N,N-Bis(benzimidazolylpicolinoyl)piperazine (BT-11): a novel lanthionine synthetase $\mathrm{C}$-like 2-based therapeutic for inflammatory bowel disease. J Med Chem (2016) 59(22):10113-26. doi:10.1021/acs.jmedchem.6b00412

76. Jarry A, Bossard C, Sarrabayrouse G, Mosnier JF, Laboisse CL. Loss of interleukin-10 or transforming growth factor beta signaling in the human colon initiates a T-helper 1 response via distinct pathways. Gastroenterology (2011) 141(5):1887-96.e1-2. doi:10.1053/j.gastro.2011.08.002

77. Vigliarolo T, Guida L, Millo E, Fresia C, Turco E, De Flora A, et al. Abscisic acid transport in human erythrocytes. J Biol Chem (2015) 290(21):13042-52. doi:10.1074/jbc.M114.629501 
78. Boursiac Y, Leran S, Corratge-Faillie C, Gojon A, Krouk G, Lacombe B. ABA transport and transporters. Trends Plant Sci (2013) 18(6):325-33. doi:10.1016/j.tplants.2013.01.007

79. Vigliarolo T, Zocchi E, Fresia C, Booz V, Guida L. Abscisic acid influx into human nucleated cells occurs through the anion exchanger AE2. Int JBiochem Cell Biol (2016) 75:99-103. doi:10.1016/j.biocel.2016. 03.006

80. Sturla L, Mannino E, Scarfi S, Bruzzone S, Magnone M, Sociali G, et al. Abscisic acid enhances glucose disposal and induces brown fat activity in adipocytes in vitro and in vivo. Biochim Biophys Acta (2017) 1862(2):131-44. doi:10.1016/j.bbalip.2016.11.005

81. Hashmi S, Ahmed M, Murad MH, Litzow MR, Adams RH, Ball LM, et al. Survival after mesenchymal stromal cell therapy in steroid-refractory acute graft-versus-host disease: systematic review and meta-analysis. Lancet Haematol (2016) 3(1):e45-52. doi:10.1016/S2352-3026(15)00224-0

82. Lu P, Hontecillas R, Philipson CW, Bassaganya-Riera J. Lanthionine synthetase component C-like protein 2: a new drug target for inflammatory diseases and diabetes. Curr Drug Targets (2014) 15(6):565-72. doi:10.2174/13894501 15666140313123714
83. Bassaganya-Riera J, Skoneczka J, Kingston DGJ, Krishnan A, Misyak SA, Guri AJ, et al. Mechanisms of action and medicinal applications of abscisic acid. Curr Med Chem (2010) 17(5):467-478. doi:10.2174/092986710790226110

84. Li H-H, Hao R-L, Wu S-S, Guo P-C, Chen C-J, Pan L-P, et al. Occurrence, function and potential medicinal applications of the phytohormone abscisic acid in animals and humans. Biochem Pharmacol (2011) 82(7):701-12. doi:10.1016/j.bcp.2011.06.042

Conflict of Interest Statement: RH and JR hold patents for the use of abscisic acid in treating disease. The other authors declare no conflict of interest.

Copyright () 2017 Zocchi, Hontecillas, Leber, Einerhand, Carbo, Bruzzone, TubauJuni, Philipson, Zoccoli-Rodriguez, Sturla and Bassaganya-Riera. This is an open-access article distributed under the terms of the Creative Commons Attribution License (CC BY). The use, distribution or reproduction in other forums is permitted, provided the original author(s) or licensor are credited and that the original publication in this journal is cited, in accordance with accepted academic practice. No use, distribution or reproduction is permitted which does not comply with these terms. 